\title{
Chemical Imaging of the Cell Membrane by NanoSIMS
}

\author{
P.K. Weber,* M.L. Kraft, ${ }^{* *}$ J.F. Frisz, ${ }^{* *}$ K.J. Carpenter, ${ }^{*}$ and I.D. Hutcheon* \\ * G.T. Seaborg Institute and Chemical Sciences Division, Lawrence Livermore National Laboratory, \\ Livermore, CA 94550 \\ ** Department of Chemical and Biomolecular Engineering, University of Illinois, Urbana- \\ Champaign, Urbana, IL 61801
}

The existence of lipid microdomains and their role in cell membrane organization are currently topics of great interest and controversy. The cell membrane is composed of a lipid bilayer with embedded proteins that can flow along the two-dimensional surface defined by the membrane[1, 2]. Microdomains, known as lipid rafts, are believed to play a central role in organizing this fluid system, enabling the cell membrane to carry out essential cellular processes, including protein recruitment and signal transduction [2,3]. Lipid rafts are also implicated in cell invasion by pathogens, as in the case of the HIV $[4,5]$. Therefore, understanding the role of lipid rafts in cell membrane organization not only has broad scientific implications, but also has practical implications for medical therapies.

One of the major limitations on lipid organization research has been the inability to directly analyze lipid composition without introducing artifacts and at the relevant length-scales of tens to hundreds of nanometers [6]. Fluorescence microscopy is widely used due to its sensitivity and specificity to the labeled species [7,8], but only the labeled components can be observed, fluorophores can alter the behavior of the lipids they label [9], and the length scales relevant to imaging cell membrane domains are between that probed by fluorescence resonance energy transfer (FRET) imaging $(<10$ $\mathrm{nm}$ ) and the diffraction limit of light. Topographical features can be imaged on this length scale by atomic force microscopy (AFM) [9-11], but the chemical composition of the observed structures cannot be determined. Immuno-labeling can be used to study the distribution of membrane proteins at high resolution, but not lipid composition. We are using imaging mass spectrometry by secondary ion mass spectrometry (SIMS) in concert with other high resolution imaging methods to overcome these limitations $[12,13]$.

The experimental approach of this project is to combine molecule-specific stable isotope labeling with high-resolution SIMS using a Cameca NanoSIMS 50 to probe membrane organization and test microdomain hypotheses[12]. The NanoSIMS is an imaging secondary ion mass spectrometer with an unprecedented combination of spatial resolution, sensitivity and mass specificity. It has $50 \mathrm{~nm}$ lateral resolution and is capable of detecting 1 in 20 nitrogen atoms while excluding near-neighbor isobaric interferences. The tightly focused cesium ion beam is rastered across the sample to produce simultaneous, quantitative digital images of up to five different masses. By labeling each specific components of a membrane with a unique rare stable isotope or element and mapping the location of the labels with the NanoSIMS, the location of the each labeled component can be determined and quantified [14-16].

This new approach to membrane composition analysis allows molecular interactions of biological membranes to be probed at length-scales relevant to lipid rafts $(10 \mathrm{~s}$ to $100 \mathrm{~s}$ of $\mathrm{nm})$ that were not 
previously possible [6]. Results from our most recent experiments analyzing whole cells will be presented.

References

[1] S. J. Singer and G. L. Nicolson, Science 175 (1972) 720-731.

[2] M. Edidin, Nature Reviews Molecular Cell Biology 4 (2003) 414-418.

[3] K. Simons and D. Toomre, Nature Reviews Molecular Cell Biology 1 (2000) 31-39.

[4] O. W. Lindwasser and M. D. Resh, Proceedings of the National Academy of Sciences (USA) 99 (2002) 13037-13042.

[5] A. Ono and F. E.O., Proceedings of the National Academy of Sciences 98 (2001) 1392513930.

[6] J. T. Groves, Science 313 (2006) 1901-1902.

[7] J. Korlach, P. Schwille, W. W. Webb and G. W. Feigenson, Proceedings of the National Academy of Sciences (USA) 96 (1999) 8461-8466.

[8] C. Dietrich, Z. N. Volovyk, M. Levi, N. L. Thompson and K. Jacobson, Proceedings of the National Academy of Sciences (USA) 98 (2001) 10642-10647.

[9] J. E. Shaw, R. F. Epand, R. M. Epand, R. B. Z. Li and C. M. Yip, Biophysical Journal 90 (2006) 2170-2178.

[10] C. Yuan and L. J. Johnston, Biophysical Journal 81 (2001) 1059-1069.

[11] L. F. Chi, M. Anders, H. Fuchs, R. R. Johnston and H. Ringsdorf, Science 259 (1993) 213216.

[12] S. G. Boxer, M. L. Kraft and P. K. Weber, Annual Review of Biophysics 38 (2009) 53-74.

[13] M. E. Kurczy, P. D. Piehowski, C. T. V. Bell, M. L. Heien, N. Winograd and A. G. Ewing, Proceedings of the National Academy of Sciences (USA) 107 (2010) 2751-2756.

[14] M. L. Kraft, S. F. Fishel, C. G. Marxer, P. K. Weber, I. D. Hutcheon and S. G. Boxer, Applied Surface Science 252 (2006) 6950-6956.

[15] M. L. Kraft, P. K. Weber, M. L. Longo, I. D. Hutcheon and S. G. Boxer, Science 313 (2006) 1948-1951.

[16] C. Galli-Marxer, M. L. Kraft, P. K. Weber, I. D. Hutcheon and S. G. Boxer, Biophysical Journal 88 (2005) 2965-2975.

[17] This research was supported by LLNL Laboratory Directed Research and Development under the auspices of the U.S. Department of Energy under Contract DE-AC52-07NA27344. 